\title{
Transmission of Legionnaires' Disease through Toilet Flushing
}

Jeanne Couturier, Christophe Ginevra, Didier Nesa, Marine Adam, Cyril Gouot, Ghislaine Descours, Christine Campèse, Giorgia Battipaglia, Eolia Brissot, Laetitia Beraud, Anne-Gaëlle Ranc, Sophie Jarraud, Frédéric Barbut

We describe 2 cases of healthcare-associated Legionnaires' disease in patients in France hospitalized 5 months apart in the same room. Whole-genome sequencing analyses showed that clinical isolates from the patients and isolates from the room's toilet clustered together. Toilet contamination by Legionella pneumophila could lead to a risk for exposure through flushing.

Tegionella pneumophila is a gram-negative bacterium Lusually found in small amounts in water in both nature and built environments. In larger amounts, it can be responsible for a severe pneumonia known as Legionnaires' disease (LD). Transmission usually occurs when someone inhales contaminated aerosols from showers, cooling towers, faucets, or fountains. Person-toperson transmission is extremely rare (1). Researchers have shown evidence of a variety of other uncommon sources of contamination, such as windshield washer fluid (2) or dental unit waterlines (3). LD transmission through flushing toilets has also been suspected (4) but not demonstrated. We report 2 cases of LD in immunocompromised patients in France, potentially caused by L. pneumophila transmission through flushing toilets.

\section{The Study}

In the first case, an 18-year-old woman who had undergone an allogeneic bone marrow transplant for acute myeloid leukemia in February 2014 in a hospital hematology unit in France was hospitalized in December 2015 in the same unit for 9 days. At that time, she

Author affiliations: Hôpital Saint-Antoine, Paris, France (J. Couturier,

D. Nesa, M. Adam, C. Gouot, G. Battipaglia, E. Brissot, F. Barbut);

Faculté de Pharmacie de Paris, Université de Paris, France

(J. Couturier, F. Barbut); Centre National de Référence des Légionelles, Lyon, France (C. Ginevra, G. Descours, L. Beraud, A.-G.

Ranc, S. Jarraud); Université Claude Bernard Lyon 1, Villeurbanne, France (C. Ginevra, G. Descours, L. Beraud, A.-G. Ranc, S. Jarraud); Santé Publique France, Saint-Maurice, France (C. Campèse); Sorbonne Université, Paris, France (E. Brissot) received immunosuppressive agents (steroids, cyclosporine A, and ruxolitinib) for a chronic graft-versushost disease. She was readmitted to the hematology unit with fever $\left(38.5^{\circ} \mathrm{C}\right)$, shivering, and dyspnea 6 days after discharge. Six days later, she was transferred to the medical intensive care unit (MICU) of the same hospital with fever $\left(40^{\circ} \mathrm{C}\right)$, bilateral pneumonia, and respiratory and renal failure. The result from a L. pneumophila urinary antigen test (BinaxNOW Legionella Urinary Antigen EIA kit; Abbott, https://www.abbott.com) was positive at the time of MICU admission, leading clinicians to consider this LD case to be probably healthcare associated. Physicians successfully treated the patient with spiramycin and levofloxacin, and she was discharged from the MICU after 8 days.

In the second case, a 51-year-old man was admitted to the same hematology unit in May 2016 for an autologous transplant for a recurrent Hodgkin lymphoma. A persistent fever $\left(38.8^{\circ} \mathrm{C}\right)$ appeared on the 12th day after admission and a computed tomography scan of the chest showed a multifocal consolidation. The result from a L. pneumophila urinary antigen test (BinaxNOW) on day 22 was positive; therefore, this LD case was considered to be definitely healthcare associated. The patient's condition suddenly worsened, and he was transferred to the MICU, where he rapidly recovered after doctors treated him with spiramycin and levofloxacin.

For both patients, a bronchoalveolar lavage procedure found L. pneumophila bacteria from serogroup 1 (LP1), pulsed-field gel electrophoresis pulsotype Paris, sequence type (ST) 1, monoclonal antibody subgroup Philadelphia. Both patients had been hospitalized in the same room (room 1) of the hematology unit, 5 months apart. Air filtration systems with HEPA filters were used to control the environment of the unit. Water from the sink in each room and from the shower, shared by all of the unit's patients, was filtered through $0.1-\mu \mathrm{m}$ pore filters. Both patients were provided only bottled water and did not take 
showers during their hospital stay. In addition, there was no cooling tower within the hospital.

We sampled and analyzed the potential sources of exposure in accordance with the NF T 90-431 standard (Association Française de Normalisation, https:/ /www.afnor.org) for counting Legionella spp., after the second LD case. In brief, we sampled $500 \mathrm{~mL}$ of water in sterile vials containing $20 \mathrm{mg}$ sodium thiosulfate. First, we inoculated $0.2 \mathrm{~mL}$ of water on GVPC (glycine, vancomycin, polymyxin, cycloheximide) plates (Oxoid France, http://www.oxoid.com/fr/ blue/). Then, we filtered $10 \mathrm{~mL}$ and $100 \mathrm{~mL}$ of water through $0.2-\mu \mathrm{m}$ pore polycarbonate membranes placed on GVPC media. We incubated plates at $36^{\circ} \mathrm{C}$ $\left( \pm 2^{\circ} \mathrm{C}\right)$ for $8-11$ days. We subcultured suspicious colonies on buffered charcoal yeast extract media with and without cystein and identified them by latex agglutination (Oxoid France).

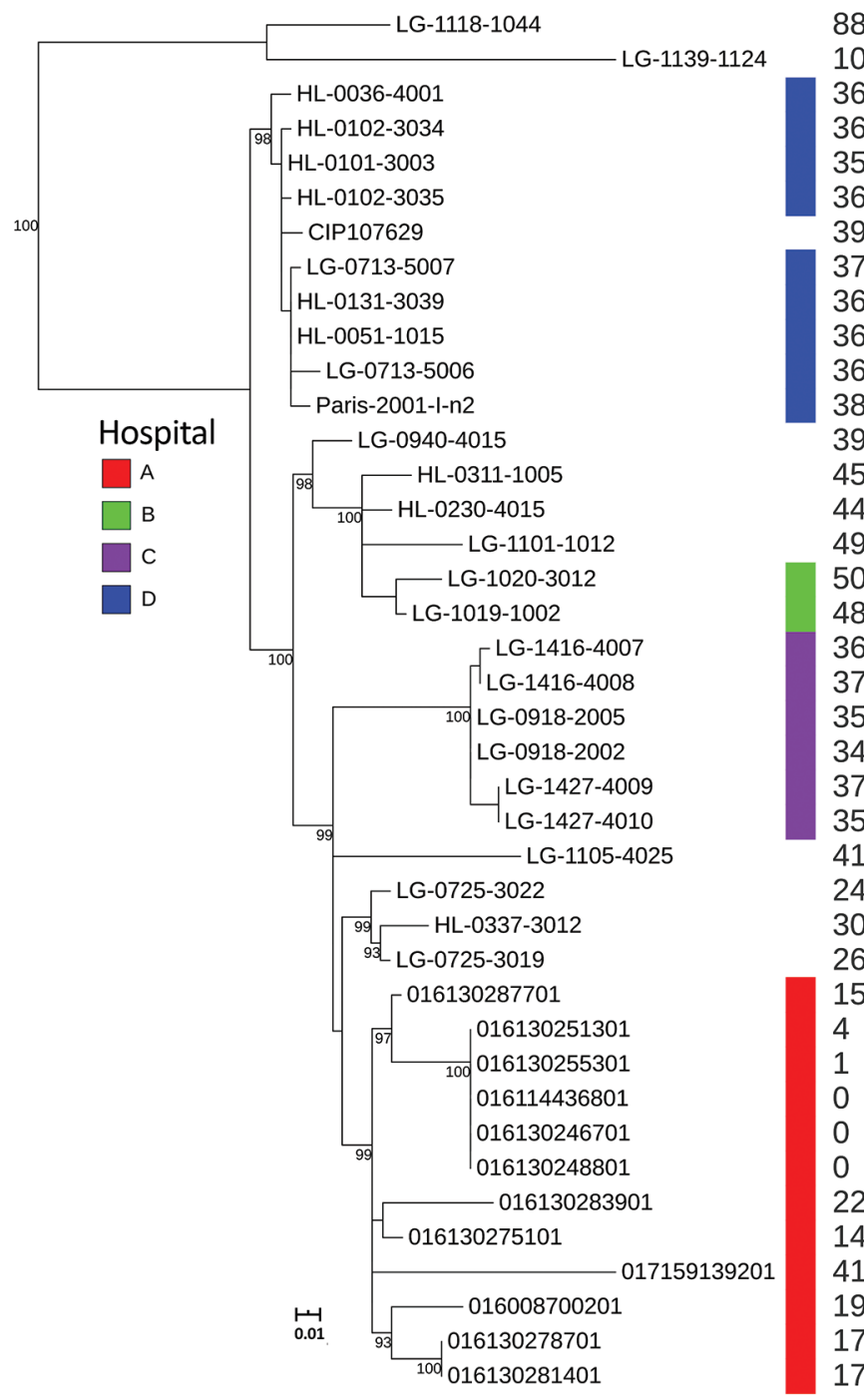

We found no L. pneumophila in the hot water from the shared shower (temperature $26.0^{\circ} \mathrm{C}$, chlorine 1.12 $\mathrm{mg} / \mathrm{L})$, nor in the hot or cold water from the sink in room 1 (temperatures $24^{\circ} \mathrm{C}$ and $25^{\circ} \mathrm{C}$, chlorine 1.11 $\mathrm{mg} / \mathrm{L}$ and $0 \mathrm{mg} / \mathrm{L}$, respectively). However, sampling of the water from the toilet bowl in room 1 showed contamination $(1,100 \mathrm{CFU} / \mathrm{L} \mathrm{LP} 1$, with a temperature of $22.0^{\circ} \mathrm{C}$ and no chlorine). LP1 was also in the toilet bowl of the adjacent room (room 2) (100 CFU/L, temperature $24.4^{\circ} \mathrm{C}$ ), the hot water from the sink in the nurses' office (10 CFU/L, temperature $49.8^{\circ} \mathrm{C}$, chlorine $0.77 \mathrm{mg} / \mathrm{L}$ ), and the cold-water inlet of the building $(20 \mathrm{CFU} / \mathrm{L}$, temperature $\left.15.0^{\circ} \mathrm{C}\right)$. Contamination in the cold-water inlet (20 CFU/L, temperature $9.0^{\circ} \mathrm{C}$ ) had also been detected in March 2016. Tests of samples of toilet water from tanks in nearby rooms did not show any contamination.

The room was closed, and the toilet was disinfected daily with bleach. The toilet water in the room was

88

104

36

36

35

36

39

37

36

36

36

38

39

45

44

49

50

48

36

37

35

34

37

35

41

24

30

26

15 Cold-water network inlet

Room 1 - toilet water

Room 1 - toilet water

Patient 2

Room 1 - toilet water

Room 1 - toilet water

Cold-water network inlet

Office ward

Cold-water network inlet (March)

Patient 1

Room 2 - toilet water

Room 2 - toilet water
Figure. Maximum-likelihood tree of 39 Legionella pneumophila ST1 isolates, including isolates from investigation of 2 cases of healthcare-associated Legionnaires' disease in patients in France hospitalized 5 months apart in the same room (red bar). The tree was constructed using 258 single-nucleotide polymorphisms (SNPs) identified after the removal of recombination events. Bootstrap values were calculated from 500 replicates; only values $>90$ were indicated on the tree. Values at the right side of the tree represent the number of SNPs between the genome compared with the genome of patient 2 after recombination removal. 
monitored through iterative testing; results were negative from 10 successive samples tested between June 2016 and November 2017. To determine the extent of such contamination, 29 toilets in 5 different hospital buildings were analyzed. All samples were negative, suggesting that L. pneumophila contamination of toilet water was not common.

We used Nextera XT technology (Illumina, https:/ / www.illumina.com) for whole-genome sequencing of 2 clinical and 10 environmental LP1 strains and deposited raw reads into the European Nucleotide Archive (study accession no. PRJEB32615). We used SPAdes to assemble genomes (5) and mompS tool to extract STs from the WGS data (6). All 12 strains belonged to ST1. We analyzed these 12 strains in more depth by comparing their genomes to 27 other epidemiologically unrelated LP1 ST1 genomes from France available in the Sequence Read Archive database (Figure; Appendix, https:// wwwnc.cdc.gov/EID/article/26/7/19-0941-App1. pdf). We also performed phylogenetic analyses on this genome's dataset, as described by David et al. (7).

The 2 clinical isolates were nested within and thus derived from the clade of isolates sampled from the hospital water network. All 12 strains, including the strains isolated in the cold-water inlet, were part of a cluster sharing the same most recent common ancestor (Figure). We observed no difference in singlenucleotide polymorphisms (SNPs) between the 2 isolates from the toilet water from the patients' room and the isolate of the second patient (Figure). The strains present in the toilet water were identical or closely related to the strains infecting the patients, and no other potential contamination source was identified, strongly suggesting that the toilet water was the contamination source. The few differences in SNPs between the first clinical isolate and the isolates found in the environment (0-23 SNPs; see Appendix Table) could be explained by diversity of the ST1 population in the water network or the micro-evolution of the environmental LP1 population during the 5 months between the $2 \mathrm{LD}$ cases (7).

\section{Conclusions}

We describe 2 cases in which LD was probably caused by L. pneumophila transmitted through contaminated toilet water that became aerosolized during flushing. We reached this conclusion because we found little to no detectable difference between whole genomes in isolates obtained from 2 patients hospitalized 5 months apart in the same room and those from the toilet in that room. The other commonly suspected sources, in this case the shower and the sink, tested negative for L. pneumophila.
This investigation suggests that transmission of L. pneumophila through toilet flushing should be considered when investigating a LD case. However, as previously suggested, there remains a need for a laboratory-based study to explore whether flushing toilets can generate and spread contaminated aerosols $(8,9)$.

\section{About the Author}

Dr. Couturier is a medical biologist at the Saint-Antoine Hospital, and a teaching assistant at the René Descartes Faculty of Pharmacy, Paris, France. Her research interests include microbiology and hospital hygiene.

\section{References}

1. Correia AM, Ferreira JS, Borges V, Nunes A, Gomes B, Capucho R, et al. Probable person-to-person transmission of Legionnaires' disease. N Engl J Med. 2016;374:497-8. https://doi.org/10.1056/NEJMc1505356

2. Prussin AJ II, Schwake DO, Marr LC. Ten questions concerning the aerosolization and transmission of Legionella in the built environment. Build Environ. 2017;123:684-95. https://doi.org/10.1016/j.buildenv.2017.06.024

3. Lauritano D, Nardone M, Gaudio RM, Candotto V, Carinci F. Risk assessment of colonization of Legionella spp. in dental unit waterlines. Oral Implantol (Rome). 2017;10:283-8. https://doi.org/10.11138/orl/2017.10.3.283

4. Hamilton KA, Hamilton MT, Johnson W, Jjemba P, Bukhari Z, LeChevallier M, et al. Health risks from exposure to Legionella in reclaimed water aerosols: toilet flushing, spray irrigation, and cooling towers. Water Res. 2018;134:261-79. https:/ / doi.org/10.1016/j.watres.2017.12.022

5. Bankevich A, Nurk S, Antipov D, Gurevich AA, Dvorkin M, Kulikov AS, et al. SPAdes: a new genome assembly algorithm. J Comput Biol. 2012;19:455-77. https:/ / doi.org/ 10.1089/cmb.2012.0021

6. Gordon M, Yakunin E, Valinsky L, Chalifa-Caspi V, Moran-Gilad J; ESCMID Study Group for Legionella Infections. A bioinformatics tool for ensuring the backwards compatibility of Legionella pneumophila typing in the genomic era. Clin Microbiol Infect. 2017;23:306-10. https:// doi.org/ 10.1016/j.cmi.2017.01.002

7. David S, Afshar B, Mentasti M, Ginevra C, Podglajen I, Harris SR, et al. Seeding and establishment of Legionella pneumophila in hospitals: implications for genomic investigations of nosocomial Legionnaires' disease. Clin Infect Dis. 2017;64:1251-9. PubMed https://doi.org/10.1093/ cid/cix153

8. Hines SA, Chappie DJ, Lordo RA, Miller BD, Janke RJ, Lindquist HA, et al. Assessment of relative potential for Legionella species or surrogates inhalation exposure from common water uses. Water Res. 2014;56:203-13. https://doi.org/10.1016/j.watres.2014.02.013

9. Johnson D, Lynch R, Marshall C, Mead K, Hirst D. Aerosol generation by modern flush toilets. Aerosol Sci Technol. 2013; 47:1047-57. https://doi.org/10.1080/02786826.2013.814911

Address for correspondence: Jeanne Couturier, Laboratoire de Microbiologie de l'Environnement, Hôpital Saint-Antoine, 184 rue du Faubourg Saint-Antoine, 75012, Paris, France; email: jeanne.couturier@aphp.fr 